\section{References}

Bannerman, R.M., Graf. C.J. \& Upson, J.F. (1967) Ehlers-Danlos syndrome. British Medical Journal, 3, 558,

Barabas, A.P. (1967) Heterogeneity of the Ehlers-Danlos syndrome: description of three clinical types and a hypothesis to explain the basic defect(s). British Medical Journal, 2, 612 .

Barabas, A.P. (1972) Vascular complications in the EhlersDanlos syndrome. Journal of Cardiovascular Surgery, 13, 160.

Beighton, P. (1968) Lethal complications of the EhlersDanlos syndrome. British Medical Journal, 3, 656.

Beighton, P. (1970) The Ehlers-Danlos Syndrome. William Heinemann, London.

Beighton, P. \& Horan, F.T. (1969) Surgical aspects of the Ehlers-Danlos syndrome. British Journal of Surgery, 56, 255.

Bopp, P., Hatam, K. \& Bussat, P. (1965) Cardiovascular aspects of the Ehlers-Danlos syndrome. Circulation, 32, 602.

EastcotT, H.H.G. (1973) Arterial Surgery. Second Edn, p. 135. Pitman Medical, London.

Graf, C.J. (1965) Spontaneous carotid-cavernous fistula. Archives of Neurology, 13, 662.
Lynch, H.T., Larsen, A.L., Wilson, R. \& Magnuson, C.L. (1965) Ehlers-Danlos syndrome and 'congenital' arteriovenous fistulae. Journal of the American Medical Association, 194, 1011.

McFarland, W. \& Fuller, D.E. (1964) Mortality in Ehlersr Danlos syndrome due to spontaneous rupture of large arteries. New England Journal of Medicine, 271, 1309.

McKusick, V.A. (1972) Heritable Disorders of Connective Tissue. Third Edn, pp. 292-371. C. V. Mosby, St Louis.

Mirza, M., Hassan, A. \& Jordan, P. (1972) Spontaneous rupture of the abdominal aorta. Annals of Thoracic Surgery, 13, 261.

MORIES, A. (1960) Ehlers-Danlos syndrome with a report of a fatal case. Scottish Medical Journal, 5, 269.

Rubinstein, M.K. \& Cohen, N.H. (1964) Ehlers-Danlos syndrome associated with multiple intra-cranial aneurysms. Neurology, 14, 125.

RyBKA, F.J. \& O'HARA, E.T. (1967) Surgical significance of the Ehlers-Danlos syndrome. American Journal of Surgery, 113, 431.

Schoolman, A. \& KePes, J.J. (1967) Bilateral spontaneous carotid-cavernous fistulae in the Ehlers-Danlos syndrome. Journal of Neurosurgery, 26, 82.

\title{
Acute appendicitis in association with non-obstructive carcinoma of the caecum
}

\author{
D. G. WALLER* \\ M.B., B.S.
}

\section{Glasgow $\dagger$ F.R.C.S.}

\section{The London Hospital, Whitechapel, London}

\begin{abstract}
Summary
A case of carcinoma of the caecum is reported, which presented as acute appendicitis, although the carcinoma did not obstruct either the lumen of the appendix or the colon.

The prognosis for caecal or proximal colonic neoplasm presenting as appendicitis is poor. This is in part due to the association being missed at the initial laparotomy. It is suggested that a more aggessive attitude should be taken in the pre- and post-operative management of any patient over 50 years of age who presents with appendicitis. The difficulties of identifying a small tumour at laparotomy even if the mucosa can be palpated are emphasized.
\end{abstract}

\section{Introduction}

The association of carcinoma of the caecum and appendicitis is well recognized. Shears in 1906 was

\footnotetext{
* Present address: Department of Haematology, Southampton General Hospital, Hants.

$\dagger$ Present address: Department of Orthopaedics, University College Hospital, London.
}

the first to report a case, although reference had been made in textbooks before the report. However, by 1967 Runderman, Strawbridge and Bloom were able to collect only seventy-one cases from the world literature.

Appendicitis is caused by obstruction of the appendical lumen in over $50 \%$ of cases (Collins, 1939). As caecal neoplasma make up $6.5 \%$ of all colonic neoplasma (Hellsten and Ramstrom, 1951) it is, therefore, reasonable to suggest that the association of appendicitis and proximal colonic neoplasm occurs more commonly than the literature would suggest. Several mechanisms have been proposed whereby colonic neoplasia may cause inflammation of the appendix (Table 1). In previous reports, the most common cause of appendicitis in association with colonic neoplasia is obstruction of the lumen of the appendix by a caecal neoplasm, although lesions causing colonic obstruction may also lead to appendicitis (Miln and McLaughlin, 1969). The authors have added extralumenal obstruction as they feel that in the case described, obstruction was due to 
TABLE 1. Causes of appendicitis in colonic neoplasms

Intra-lumenal obstruction of the appendix.

Extra-lumenal obstruction of the appendix.

Abscess formation.

Lymphatic infiltration.

Tumour infiltration spreading to involve the appendix.

Secondary involvement of the appendix with tumour.

kinking of the appendix resulting from its attachment to the inflamed serosa overlying the caecal tumour. As well as causing appendicitis, proximal colonic neoplasms, particularly caecal, may stimulate appendicitis. In a review of 122 cases of caecal carcinoma, Costello and Saxton (1951) found that thirty-one cases had presented with suspected appendicitis, and this figure included patients in whom the symptoms were due to abscess formation, caecal perforation or local inflammation related to the tumour.

\section{Case report}

A 50-year-old woman was admitted with a 36-hr history of abdominal pain, initially central, but later localizing in the right iliac fossa. During this period she had vomited three times and had absolute constipation. There were no preceding episodes of abdominal pain or distension and her bowels had been regular until the onset of symptoms. On further questioning she admitted to a 4-month history of increasing shortness of breath and palpitations. She had no history of weight-loss and her appetite was normal. On examination she was well nourished, but clinically anaemic with a temperature of $38^{\circ} \mathrm{C}$. She had a bounding pulse rate of $100 / \mathrm{min}$ and a systolic flow murmur. Her abdomen was tender, with guarding in the region of McBurney's point. No abdominal mass was palpable and rectal examination was unhelpful. Investigations included chest and abdominal X-rays which showed no abnormality. The haemoglobin level was $9.0 \mathrm{~g} / \mathrm{dl}$, with a mean corpuscular volume of 61 and a haematocrit of $28 \cdot 8$. The white cell count was $13,700 / \mathrm{mm}^{3}$, mainly neutrophil polymorphs.

A diagnosis of acute appendicitis was made and on the evening of admission, a laparotomy was performed through a gridiron incision. At operation there was a small amount of turbid fluid in the peritoneal cavity. An inflammatory mass, consisting of omentum, and an acutely inflamed appendix was found aherent to the anterolateral aspect of the caecum approximately $4 \mathrm{~cm}$ from the appendix base. There was no evidence of caecal obstruction. Separation of the adherent mass from the caecal wall revealed a hole in the caecum. Suspicion of malignancy was aroused and careful digital examination of the caecal mucosa was performed through the hole. There was marked inflammatory oedema pre- sent, and the mucosal folds were grossly thickened. It was consequently impossible to determine whether or not a tumour was present. Three random biopsies were therefore taken, and the caecal defect closed in two layers. The appendix was acutely inflamed with a gangrenous tip and there was noted to be a kink at the base due to the attachment of the distal end to the caecal wall. Following routine appendicectomy, the abdominal wall was closed with drainage of the peritoneal cavity.

Subsequent histology reports confirmed the clinical findings in the appendix with no evidence of tumour. The mucosal biopsies revealed necrotic, moderately differentiated adenocarcinoma.

Nine days after the initial operation, the patient underwent a formal right hemicolectomy. At laparotomy, the liver and nodes were free of tumour. She made a good postoperative recovery and is well at the time of writing.

The specimen revealed macroscopically an obvious carcinoma (Fig. 1) and sections confirmed the original histology, with invasion of the caecal wall to serosa, but no nodal involvement.

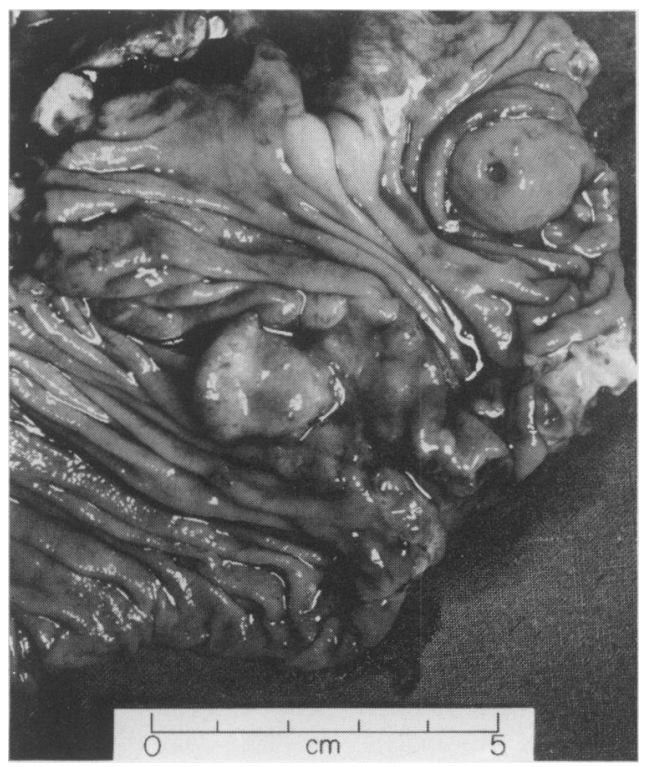

FIG. 1.

\section{Discussion}

The prognosis of caecal tumours presenting as appendicitis is poor, in Patterson's (1956) series of seventeen cases, ten were dead within 14 months. This may in part be due to the nature of the tumour; however, delay in diagnosis undoubtedly accounts for some deaths. Reviewing the literature, in only $35 \%$ of the cases described to date was a tumour correctly diagnosed at the original laparotomy, and in other 
cases the average time from initial surgery to resection of the tumour was over 4 months. This problem has been recognized since 1947, when Mayo noted that $15 \%$ of patients with caecal neoplasms had undergone previous appendicectomy for symptoms which in retrospect were probably attributable to the tumour.

Large neoplasms are easy to diagnose at laparotomy for appendicitis but there remain the small, early tumours. The most important aspect in management is to realize that patients are liable to have an underlying tumour. Colonic tumours are rarely found in patients under the age of 50 years and conversely, appendicitis is unusual above this age. In a random series of 329 appendicectomies reported by Miln and McLaughlin (1969) only fifteen patients were over 50 years of age. Therefore, a colonic neoplasm should be suspected in any patient over the age of 50 years presenting with signs or symptoms of appendicitis. In this group, particular note should be taken of a history suggesting anaemia, weightloss or colonic obstruction.

On examination, the signs of acute appendicitis usually dominate the clinical picture, although a mass in the right iliac fossa should always be regarded with suspicion. Frequently, however, there will be no signs or symptoms referable to the tumour.

If the patient is over 50 years and there is any factor in the history or examination which suggests that a tumour may be present then there is a strong case for a right paramedian incision. In appendicitis, the caecum may well be thickened and oedematous as a result of local inflammatory reaction and, in this situation, even if there is a caecotomy, as in the case described, it is not always possible to exclude a tumour. Certainly palpation of the intact caecum is not an adequate means of assessment. If the caecum is abnormal in any way, an exploratory caecotomy and mucosal biopsy are strongly advocated. If possible, surgery should be undertaken where facilities for frozen section are available. In the event of an abscess being present, the pus should be examined for neoplastic cells and the abscess wall biopsied (Miller and Wooldridge, 1954).
If the presence of a tumour is confirmed, every attempt should be made to perform a right hemicolectomy at the initial operation. Ideally, continuity of bowel should be established without a defunctioning outlet, although this may be necessary in cases with fulminant abscess formation. In cases where no tumour is found at appendicectomy, development in the postoperative period of a faecal fistula or a persistent mass in the right iliac fossa should encourage early re-exploration. Unfortunately, these signs are frequently ignored, leading to an unnecessary delay in diagnosis of an underlying tumour, in a site always difficult to examine radiologically.

Finally, the authors suggest a careful follow-up of all patients over 50 years who are admitted with appendicitis. Postoperative follow-up investigations should include barium enema or colonoscopy, haemoglobin estimations and the periodic testing of stools for occult blood.

\section{References}

BURT, C.A.V. (1949) Carcinoma of cecum complicated by appendicitis or paracecal abscess. Surgery, Gynecology and Obstetrics, 88, 501.

Collins, D.C. (1939) Aetiological factors in acute appendicitis based upon a study of 3,400 cases. Surgery. St Louis, etc., 5, 267.

Costello, O. \& Saxton, J. (1951) Appendicitis and cancer Postgraduate Medicine, 9, 482.

Hellsten, H. \& Ramstrom, S. (1951) Coexistent caecal cancer and appendicular abscess. American Medical Association Archives of Surgery, 62, 112.

Mayo, C.W. (1947) Carcinoma of the right (proximal) portion of the colon. Surgical Clinics of North America, $27,875$.

Miller, C. \& Wooldridge, B.F. (1954) Acute appendicitis with abscess formation as a complication of carcinoma of the caecum. American Journal of Surgery, 88, 500.

Miln, D.C. \& Mclaughlin, I.S. (1969). Carcinoma of proximal large bowel associated with acute appendicitis. British Journal of Surgery, 56, 143.

Patterson, H.A. (1956) The management of caecal cancer discovered unexpectedly at operation for acute appendicitis. Annals of Surgery, 143, 670.

Runderman, R.L., Strawbridge, H.T.G. \& Bloom, H.W. (1967) Carcinoma of the caecum, presenting as acute appendicitis. Canadian Medical Association Journal, 96, 1327.

\section{Errata}

Supplement 8, 1976, vol. 52. 'Infant milk powder feeds compared in a common basis' A. E. Mettler.

The author has drawn our attention to the following errors in his manuscript:

\section{Table 6}

Values for P: for $\mathrm{g}$ read $\mathrm{mg}$; Gold Cap SMA S26: values for $\mathrm{Na}+\mathrm{K} \mathrm{mEq}$ per litre: for 16.7 read $24 \cdot 2$.

\section{Table 7}

Gold Cap SMA S26: values for $\mathrm{Na}+\mathrm{K}$ mEq per litre: for 3.8 read 3.6.

\section{Table 14}

For heading 'Sweetness equivalent $\mathbf{g}$ of sucrose per $100 \mathrm{ml}$ ' read 'Sweetness equivalent $\mathrm{g}$ of sucrose per $100 \mathrm{kcal}$. 